\title{
"La escultura policroma religiosa de los siglos XVII y XVIII: estudio comparativo de técnicas, alteraciones y conservación en Portugal, España y Bélgica"
}

El pasado 29 de julio fue aprobado el proyecto de Investigación "La escultura policroma religiosa de los siglos XVII y XVIII: estudio comparativo de técnicas, alteraciones y conservación en Portugal, España y Bélgica" presentado al Programa Raphael de la Unión Europea dentro de la Acción I (Conservación, salvaguarda y valorización del Patrimonio Cultural Mueble a través de la Cooperación Europea).

Este proyecto de tres años de duración se plantea con una estructura tripartita constituida por algunas de las principales instituciones dedicadas al Patrimonio Cultural de los respectivos países participantes, quedando articulada como sigue:

Organismo coorganizador Instituto de José de Figuiredo (al cual se debe la iniciativa del proyecto) y dos organismos coorganizadores, por España, el Instituto Andaluz del Patrimonio Histórico y por Bélgica, el Instituto Real del Patrimonio Artístico. A su vez, de cada uno de estos países participan diferentes Instituciones, Museos y Universidades principalmente.

Con este Proyecto se pretende cumplir una serie de objetivos relacionados con el conocimiento y la divulgación de los principales aspectos de la escultura policromada del periodo temporal abarcado, partiendo de una metodología de estudio e investigación previa y común de las Instituciones implicadas en el mismo. Estos objetivos se centran fundamentalmente en el conocimiento de estas obras a diferentes niveles: técnicos (materia- les y técnicas de ejecución y decoración), factores de alteración que inciden sobre ellas, principales patologías presentes y por último, realización de las acciones directas e indirectas que requiere tanto su conservación, como su puesta en valor.

Para ello se han seleccionado de forma preliminar por parte de cada Institución participante una serie de obras que servirán de punto de partida para definir e incentivar acciones comunes que permitan conocer este importante Patrimonio desde diferentes ámbitos, no sólo de aquellos relacionados con su conservación material, sino también con aquellos que permitan plantear una correcta Política de Actuación, Protección y Comunicación, y también de Divulgación y Comunicación de tanto a especialistas como al público en general.

En síntesis con este Proyecto pretendemos:

- Incentivar investigaciones de ámbito europeo dentro del marco de intereses patrimoniales y culturales comunes.

- Contribuir a la normalización europea de bases de datos en esta área, que sirvan de referencia o de instrumento de trabajo tanto a profesionales como en ámbito pedagógico y de formación de futuros especialistas.

- Dar continuidad a acciones de sensibilización sobre la presentación de este Patrimonio en grandes exposiciones.
- Establecer unos criterios comunes de presentación de estos bienes, reforzando aquellos aspectos eminentemente didácticos e incentivando bases homogéneas de criterios de presentación (Público y Turismo) a fin de contribuir a su conocimiento y valorización.

- Establecer colaboraciones con países de lengua española de América Central y del Sur o con Brasil.

- Establecer una cualificación profesional y de diagnóstico de estos bienes patrimoniales que garantice una adecuada capacidad de respuesta a los problemas de conservación, fomentando el intercambio de conocimientos y de especialistas.

- Definir prioridades en la salvaguarda de este Patrimonio.

El proyecto se puso en marcha en el mes de noviembre en Lisboa, ciudad en la que por vez primera se reunieron los principales representantes de las Instituciones organizadoras y participantes para establecer el programa de trabajo inicial de desarrollo de este importante Proyecto.

Ma José González López 